\section{Observations on an unusual behaviour in the Carpenter Bee Xylocopa aestuans (Latreille, 1802) (Hymenoptera: Apidae) of the Western Ghats, India}

\author{
Sachin A. Punekar ${ }^{1}$, Navneeth K.P. Kumaran ${ }^{2}$ \& \\ Hari R. Bhat \\ 1,2 Paleobiology Group, Agharkar Research Institute, \\ G.G. Agarkar Road, Pune, Maharashtra 411004, India \\ ${ }^{3}$ 107, Avanti Apartment, Opposite Kamla Nehru Park, \\ Erandwane, Pune, Maharashtra 411004, India \\ Email: sachinpunekar@gmail.com
}

The genus Xylocopa distributed in all the continents consists of 51 subgenera and about 450 species (Leys et al. 2000). The subfamily Xylocopinae has four tribes, Xylocopini, Allodapini, Ceratinini and Manuelini of which the first three tribes are represented in India and its neighbours by 43 species, under seven subgenera (Leys et al. 2000; Gupta 2008).

The bee Xylocopa aestuans under the subgenus Koptortosoma Gribodo, 1894 has been recorded from many localities in South East Asia and Africa (Gupta 2008) from deadwood, pithy stems, bamboo culms, wooden beams in the open buildings. Female or sometimes both male and female bees construct nests by digging tunnels or holes, in a week or more depending upon the substrate (Vicidomini 1997; Raju \& Rao 2006 and SAP \& HRB pers. obser.).

Observations on foraging, so far, refer to the provision

Date of publication (online): 26 September 2010

Date of publication (print): 26 September 2010

ISSN 0974-7907 (online) | 0974-7893 (print)

Editor: K.R. Sasidharan

Manuscript details:

Ms \# 02271

Received 28 July 2010

Final revised received 07 July 2010

Finally accepted 18 August 2010

Citation: Punekar, S.A., N.K.P. Kumaran \& H.R. Bhat (2010). Observations on an unusual behaviour in the Carpenter Bee Xylocopa aestuans (Latreille, 1802) (Hymenoptera: Apidae) of the Western Ghats, India Journal of Threatened Taxa 2(10): 1232-1233.

Copyright: () Sachin A. Punekar, Navneeth K.P. Kumaran \& Hari R. Bhat 2010. Creative Commons Attribution 3.0 Unported License. JoTT allows unrestricted use of this article in any medium for non-profit purposes, reproduction and distribution by providing adequate credit to the authors and the source of publication.

Acknowledgements: The authors are grateful to the Director, Aghraka Research Institute for facilities and officials of the Anshi National Park, Karnataka for permission to conduct field studies.

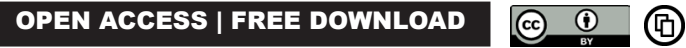

made for developmental stages by the adults. This provision mainly contains pollen mixed with nectar (Raju \& Rao 2006), popularly known as 'Bee Bread' for juveniles. In the absence of critical data, it is presumed that adults feed on the same diet as larvae. Our observations indicate an unusual feeding strategy possible in Xylocopa aestuans.

In this observation, made during June 2005, in Anshi National Park, Karnataka. As of now Xylocopa aestuans is known to feed strictly on the pollen and plant nectar and they are yet to be known to prey upon the insects. In this study we found that the bees pick up the Red Tree Ants Oecophylla smaragdina, a common ant species in the Western Ghats (Image 1A), fight against and kill, carry them away, probably to their nests (Image 1B,C). This activity raises questions (1) whether the adult female Carpenter bees are switching over to carnivory, (2) whether a seasonal strategy to tide over the non-flowering period of arborescent plants as carpenter bees mostly prefer them, (3) consume the ants and regurgitate with the harvested pollen and plant nectar to prepare more nutritious 'Bee Bread' for juveniles? Although most of the arborescent plants in Anshi National Park do not flower during June, a few plants of Syzygium caryophyllatum (Myrtaceae) bloom. And as such, there may be a competition among the pollinators and the opportunists like carpenter bees (Xylocopa spp.), butterflies (Blue Tiger, Common Crow, Rice Swift), Honey Bee (Apis dorsata) and Flower Wasp (Scolia sp.) that harvest nectar and pollen (Image 1D-I) (Punekar 2007) leading Xylocopa aestuans to forage on Red Tree Ants. Thus, phenological condition may be a stress response factor for Xylocopa aestuans or such an unusual feeding behaviour may not have been reported. Considering Xylocopa aestuans is well-known pollen and plant nectar feeder and harvesters, the unusual feeding behaviour appears to be a new phenomenon. Analysis of bee bread prepared by Xylocopa aestuans may reveal whether the foraging strategy is a seasonal or new ethological condition.

\section{REFERENCES}

Gupta, R.K. (2008). An annotated catalogue of the bee species of the Indian Region. Jai Narain Vyas University, Jodhpur. [http://www.geocities.com/beesind2/xylocopa.htm] accessed on 15 March 2009.

Leys, R., S.J.B. Cooper \& M.P. Schwarz (2000). Molecular phylogeny of the large carpenter bees, Genus Xylocopa (Hymenoptera: Apidae), based on Mitochondrial DNA sequences. Molecular Phylogenetics and Evolution 17: 407418.

Punekar, S.A. (2007). An assessment of floristic diversity of Anshi National Park, Karnataka. PhD Thesis submitted to University of Pune, Pune, India.

Raju, A.J.S. \& S.P. Rao (2006). Nesting habits, floral resources and foraging ecology of large carpenter bees (Xylocopa 

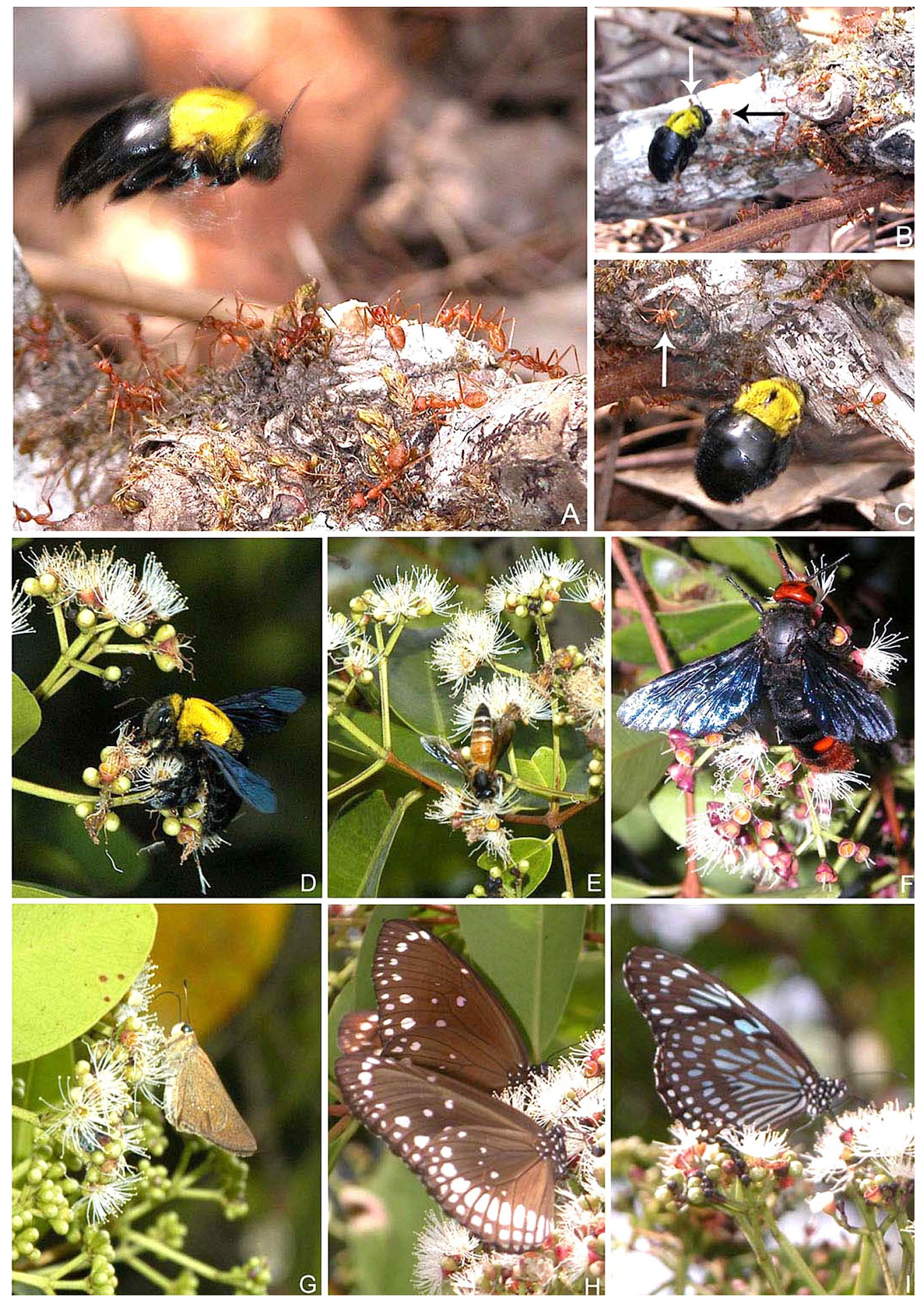

Image 1. A - Carpenter Bee (CB) approaching a swarm of Red Tree Ants (RTA); B - CB picking a RTA and carrying away (white arrow) and attacking the ant (black arrow); C - CB moving towards a swarm of RTAs and attacking the ant (white arrow); D - CB harvesting nectar and pollen from Syzygium caryophyllatum (Sc); E - Rock Bee Apis dorsata feeding on flower nectar and pollen of Sc; F - Flower Wasp (Scolia sp.) feeding on flower nectar and pollen of Sc; G - Rice Swift Butterfly Borbo cinnara feeding on flower nectar of Sc; H - Common Indian Crow Butterfly Euploea core feeding on flower nectar of Sc; I - Blue Tiger Butterfly Tirumala limniace feeding on flower nectar of Sc. @ ( Sachin A. Punekar.

latipes and Xylocopa pubescens) in India. Current Science 90: $1210-1217$.

Vicidomini, S. (1997). World bibliography on Xylocopini tribe (Insecta: Hymenoptera: Apoidea: Apidae: Xylocopinae):
Xylocopia Latreille, 1802; Lestis Lepeletier \& Serville, 1828; Proxylocopa Hedicke, 1938. La Nuova Legatoria, Cava De' Tirreni (SA), $141 \mathrm{pp}$. 